\title{
Tracking mortality in near to real time provides essential information about the impact of the COVID-19 pandemic in South Africa in 2020
}

\author{
D Bradshaw, ${ }^{1,2}$ DPhil; R E Dorrington, ${ }^{3}$ BCom, BSc Hons, BA, MPhil, FASSA; R Laubscher, ${ }^{4}$ BComm (Maths); \\ T A Moultrie, ${ }^{3}$ BBusSc, MSc, PhD; P Groenewald, ${ }^{1} \mathrm{MB} \mathrm{ChB}, \mathrm{MPH}$ \\ ${ }^{1}$ Burden of Disease Research Unit, South African Medical Research Council, Cape Town, South Africa \\ ${ }^{2}$ School of Public Health and Family Medicine, Faculty of Health Sciences, University of Cape Town, South Africa \\ ${ }^{3}$ Centre for Actuarial Research, Faculty of Commerce, University of Cape Town, South Africa \\ ${ }^{4}$ Biostatistics Unit, South African Medical Research Council, Cape Town, South Africa
}

Corresponding author: D Bradshaw (debbie.bradshaw@mrc.ac.za)

\begin{abstract}
Background. Producing timely and accurate estimates of the impact of COVID-19 on mortality is challenging for most countries, but impossible for South Africa (SA) from cause-of-death statistics.

Objectives. To quantify the excess deaths and likely magnitude of COVID-19 in SA in 2020 and draw conclusions on monitoring the epidemic in 2021.

Methods. Basic details of deaths registered on the National Population Register by the Department of Home Affairs (DoHA) are provided to the South African Medical Research Council weekly. Adjustments are made to the numbers of weekly deaths to account for non-registration on the population register, as well as late registration of death with the DoHA. The weekly number of deaths is compared with the number predicted based on the Holt-Winters time-series analysis of past deaths for provinces and metropolitan areas. Excess deaths were calculated for all-causes deaths and natural deaths, using the predicted deaths as a baseline. In addition, an adjustment was made to the baseline for natural deaths to account for the drop in natural deaths due to lockdown.

Results. We estimated that just over 550000 deaths occurred among persons aged $\geq 1$ year during 2020, 13\% higher than the 485000 predicted before the pandemic. A pronounced increase in weekly deaths from natural causes peaked in the middle of July across all ages except $<20$ years, and across all provinces with slightly different timing. During December, it became clear that SA was experiencing a second wave of COVID-19 that would exceed the death toll of the first wave. In 2020, there were $70000-76000$ excess deaths from natural causes, depending on the base. Using the adjusted base, the excess death rate from natural causes was 122 per 100000 population, with a male-to-female ratio of 0.78 . Deaths from unnatural causes halved for both males and females during the stringent lockdown level 5 . The numbers reverted towards the predicted number with some fluctuations as lockdown restrictions varied. Just under 5000 unnatural deaths were averted.

Conclusions. Tracking the weekly numbers of deaths in near to real time has provided important information about the spatiotemporal impact of the pandemic and highlights that the 28000 reported COVID-19 deaths during 2020 substantially understate the death toll from COVID-19. There is an urgent need to re-engineer the system of collecting and processing cause-of-death information so that it can be accessed in a timely way to inform public health actions.
\end{abstract}

S Afr Med J 2021;111(8):732-740. https://doi.org/10.7196/SAMJ.2021.v111i8.15809

The COVID-19 pandemic has generated unprecedented public interest in global health statistics, aided by readily accessible data aggregators and dashboards together with media and social media. However, the abundance of data on the number of confirmed COVID-19 cases and deaths obscures the severe limitations of these statistics. Triangulation of multiple data sources becomes essential to develop an understanding of the available numbers.

In explaining the value of epidemiological models, Charlie Giattino $^{[1]}$ cautions that 'A key limitation in our understanding of the COVID-19 pandemic is that we do not know the true number of infections. Instead, we only know of infections that have been confirmed by a test - the confirmed cases. But because many infected people never get tested, we know that confirmed cases are only a fraction of true infections.' To this could be added concerns about whether there are biases in the representativeness of the population where the number of tests is limited, and whether the confirmed COVID-19 deaths are a reliable reflection of the true numbers of deaths. Furthermore, there are considerable challenges related to the timing of the occurrence of cases and deaths; the daily numbers of confirmed cases and deaths are usually reported by the day the confirmation is reported, which is usually a variable number of days after infection/death.

Monitoring the excess deaths has emerged as an important approach to assess the magnitude of the impact of COVID-19, ${ }^{[2-5]}$ and tracking these numbers in near to real time provides an invaluable bird's eye view of how the pandemic is unfolding. Leon et al. ${ }^{[6]}$ suggested that real-time weekly excess deaths could provide the most objective and comparable way of assessing the scale of the pandemic and formulating lessons to be learned.

South Africa (SA) has a well-established civil registration and vital statistics system, but this is not able to provide timely cause-of-death information; ${ }^{[7]}$ the latest available report is for the year 2017, and this excludes significant late registrations. ${ }^{[8]}$ The South African Medical Research Council (SAMRC), together with the University of Cape 
Town, developed a Rapid Mortality Surveillance (RMS) system based on the deaths of people on the National Population Register (NPR) maintained by the Department of Home Affairs (DoHA). Since 2011, these data have been used to produce a set of mortality indicators by making adjustments for the general under-registration of deaths and those missing from the NPR because the person who died did not have an SA identity number (ID). ${ }^{[9]}$

There was an urgent need to be sure about how the pandemic was unfolding in the country - the extent of the impact, and the 'who, when and where?'. Without knowing the extent to which the beneficial effect of the youthful demographic structure of the population would counter the high prevalence of comorbidities and compromised immune systems, it was important to ensure that the country had a robust surveillance system. Furthermore, at the time of initiating weekly tracking of deaths, it was not clear whether there had already been any unnoticed outbreaks of the epidemic in the country. We therefore established a near real-time system to track mortality in the country.

\section{Methods}

\section{Data source}

In the event of a death, a death notification form is completed by a medical practitioner or a forensic pathologist (or a traditional leader if no medical practitioner is available and the death is due to natural causes) and submitted to the DoHA, which is responsible for civil registration in SA. The DoHA issues a burial order and an abbreviated death certificate to the family of the deceased. For all deaths of individuals who have an SA ID number or whose birth has been registered in the country, the NPR is updated as part of the registration process. Since 1999, the SAMRC has obtained monthly updates of the deaths registered on the NPR and has developed a consolidated database including basic information on age, sex, whether the cause was natural or unnatural, and the office of registration of deaths by SA ID number. Data confidentiality is maintained by using password protections and limiting access to the database. Review of these data has revealed that a high proportion of deaths ( $>95 \%)$ were registered within 2 weeks of occurrence and that the data from offices within a province, suitably reweighted, can be used to provide measures of mortality in that province. Permission was granted by the DoHA to obtain the data weekly, and regular downloads, conducted on Sundays, have been provided since 23 March 2020.

During lockdown level 5 (27 March - 30 April 2020), DoHA offices were open for limited hours (10h00 - 14h00, Monday to Friday) to continue offering essential services, including the registration of deaths. ${ }^{[10]}$ However, neither the Thusong Centres, which had been established to provide government services, including those of Home Affairs, to marginalised communities, nor the special Home Affairs offices set up in large public sector hospitals to support birth registration, operated during this period. Because the NPR does not record deaths of persons not on the NPR, all deaths of persons whose birth was not registered before death during this period were not captured by the NPR, so it was necessary to limit the estimation of excess deaths to the deaths of persons aged $\geq 1$ year. Although the exclusion of infant deaths has a limited impact on the overall number of COVID-19 deaths, the under-recording of births and neonatal and post-neonatal deaths limits our ability to measure infant mortality for 2020 .

In addition, the DoHA faced sporadic temporary office closures, particularly in areas that were most affected by COVID-19. These closures caused some delays in the processing of the death registration that, at best, result in a slight underestimation of the deaths in the most recent week being reported on. While processing starts again once the offices reopen, deaths that are never registered, or are registered in a different province, could result in an underestimate for the week in question.

\section{Analysis}

As outlined in the RMS reports, ${ }^{[9]}$ the NPR data are subject to two forms of under-reporting. The first is non-registration on the NPR (because the deceased did not have an SA birth certificate or identity document). The second is the generalised non-registration of death with the DoHA, a common challenge experienced in developing countries.

The extent of non-inclusion of deaths on the NPR has been estimated by comparing the numbers of deaths (for males and females separately) recorded on the population register at each age in a year with the numbers reported by Statistics South Africa (Stats SA) for that year from 2000 until the most recent available year (this being 2017) ${ }^{[8]}$ which include registered deaths not on the population register. Under-recording of adult deaths is estimated for periods between censuses (and sometimes national population surveys) using standard demographic methods, ${ }^{[11,12]}$ and the trend over time is extrapolated to more recent years. For children aged $<5$ years, completeness is estimated by comparing numbers of registered deaths reported by Stats SA with the numbers implied by independent estimates of child mortality from questions on child survival asked in censuses and various surveys (e.g. the 2016 South Africa Demographic and Health Survey $\left.{ }^{[13]}\right)$. The estimates of completeness for the ages between 5 and 15 years are interpolated between these two estimates.

In addition to these adjustments at the national level, it was necessary to make similar adjustments at the provincial and metropolitan district ('metro') level, and by natural and unnatural causes. Since the population register does not record place of death, the place of death was assigned to province and metro according to the location of the office at which the death was registered. The adjustment for overall incompleteness of the NPR data by sex and age was estimated on the assumptions that all deaths in metro districts and all unnatural deaths in non-metro districts reported by Stats SA are completely reported. Comparison of the deaths captured by the NPR with the estimates derived from the Stats SA data, corrected for incompleteness of death reporting, on the assumptions mentioned, provides a record of the completeness of the NPR data in the past. For the estimation of weekly excess deaths, completeness of reporting was assumed to be the same as for 2015 (the most recent year at the start of the project, which was assumed to include the bulk of late registrations).

Excess deaths were monitored on a weekly basis, with the first week starting on Wednesday 1 January 2020 (epi-weeks).

Finally, in order to provide near to real-time weekly estimates of excess deaths, it is necessary to adjust the data for the most recent week covered by the weekly update of the NPR for deaths incurred but not yet processed. Adjustment factors were determined by monitoring the proportions of the ultimately reported numbers of deaths that are processed by the end of the Friday following the Tuesday end of the epi-week in which the death occurred. To maintain the relevance of the reporting, these estimates are updated on a weekly basis to take into account how well the adjustment worked in the previous weeks and the impact of any hiatuses, such as office closures due to COVID19 or public holidays. Data for this report were extracted from the data captured up to and including the week ending 5 January 2021, to allow estimation of numbers to 31 December. 
During the scoping analysis of the data, it became clear that the weekly numbers of deaths show a strong seasonal pattern, implying that the time of the year needs to be considered in assessing whether any observed change in the number of registered deaths is usual. For this reason, the historical data from 2018 and 2019, adjusted for under-reporting, were used to predict the number of deaths that could be expected during 2020. The Holt-Winters ${ }^{[14,15]}$ method of forecasting was used in Excel (Microsoft, USA) to predict weekly numbers of deaths for 2020 based on a linear annual trend, allowing for a seasonal effect over the year. In addition, 95\% prediction intervals were estimated for the predicted weekly number of deaths for 2020 to identify significant increases in the numbers of deaths.

The World Health Organization website for Humanitarian Health Action $^{[16]}$ defines 'Excess mortality, excess mortality rate' as 'Mortality above what would be expected based on the non-crisis mortality rate in the population of interest. Excess mortality is thus mortality that is attributable to the crisis conditions. It can be expressed as a rate (the difference between observed and non-crisis mortality rates), or as a total number of excess deaths.' However, there is no standard method for calculation or presentation. In this article, we calculate the number of excess deaths using three approaches, each serving a different purpose (Table 1). The first and most general approach, using all-cause mortality, provides the overall impact of the crisis, while the second approach, using only data on natural mortality, removes the effect of lockdown on the unnatural deaths. The third approach aims to estimate the impact of the COVID-19 pandemic, taking into account the early impact of lockdown on the number of non-COVID-19 natural deaths. In this case the baseline was initially set as a percentage of the predicted number of natural deaths, that percentage being set as the ratio of the actual deaths, less confirmed COVID-19 deaths, to the predicted number of deaths during the week prior to the rapid increase in actual deaths due to COVID19. In addition, accumulated past excess deaths to that point were set equal to the accumulated past confirmed COVID-19 deaths. Towards the end of July, the baseline was modified to trend linearly to the predicted numbers over the next month or so to allow for the relaxing of lockdown conditions. Later small adjustments were made to the baseline in the Western Cape and the City of Cape Town after the winter peak, since the numbers of excess deaths fell below the confirmed number of COVID-19 deaths, and towards the end of the first wave were considerably higher than the confirmed number of confirmed COVID-19 deaths.

\section{Results}

Some noticeable delays in registration of deaths were observed in the weekly updates in April and May, particularly in Eastern Cape and Western Cape provinces. These appeared to correspond with DoHA office closures, with the bulk of these missing registrations either shifted to other offices or captured within a week or two later. From 1 January until the end of 2020, a total of 504489 deaths were recorded on the NPR, of which 495201 were for persons aged $\geq 1$ year. After adjustment for the two forms of under-reporting described, it was estimated that a total of 549921 deaths occurred among persons aged $\geq 1$ year. Based on the trends of the past 2 years, it was predicted that there would have been 485049 deaths of persons aged $\geq 1$ year for 2020. The estimate of the actual number of deaths for persons aged $\geq 1$ year for 2020 was therefore $\sim 13 \%$ higher than predicted.

Fig. 1 shows the predicted number of weekly deaths for persons aged $\geq 1$ year, with a clear increase during the winter months. It also shows a distinct drop in the weekly number of deaths during April June 2020, coinciding with the stringent level 5 lockdown in response to the pandemic. Thereafter, the weekly number increased steadily for $\sim 6$ weeks, reaching a peak of 16488 deaths during the week of 15 - 21 July 2020. This was $65 \%$ above the predicted non-COVID-19 number of 9 967, ranging from 53\% to 80\% higher than predicted, given a predicted value within the uncertainty bound of 9179 10756 that week. Following the first surge, the numbers declined and returned close to the predicted level within the next 6 weeks. After tracking close to the predicted value during September, the weekly numbers of deaths rose to exceed the upper prediction bound during October and rose rapidly from the end of November to exceed the predicted number by $81 \%$ in the last week of 2020 (uncertainty range of $64-102 \%$ ). Subsequent monitoring of the deaths (not shown) reveals that the surge of the second wave turned in the second week of January 2021, at a somewhat higher level than the first wave.

The trend in the numbers of deaths from natural causes by age group is shown in Fig. 2. A pronounced increase in the number of deaths, peaking in the middle of July, is apparent in all age groups except $<20$ years. For the 0 - 4-year-olds (i.e. including infant deaths), a marked drop was observed from April, only reaching the predicted value towards the end of the year. Deaths of persons 5 39 years of age tracked the predicted level during the initial levels of lockdown, after which there was a significant increase, peaking in the middle of July. However, this hides the fact (not shown) that the trends of the 5 - 19- and 20 - 39-year age groups are very different. Those aged 5 - 19 showed no clear trend, with the weekly number of deaths remaining within the prediction intervals throughout the year and difficult to interpret as the number of registered child deaths is confounded by a drop in the birth registrations during the lockdown. On the other hand, deaths of persons 20 - 39 years of age tracked the predicted level during the initial levels of lockdown followed by a significant increase, peaking in the middle of July at

Table 1. Different methods of calculating excess deaths

\begin{tabular}{ll}
\hline Measure of excess deaths & Purpose of measure \\
\hline 1. Actual all-cause deaths $v$. forecast all-cause deaths & $\begin{array}{l}\text { This provides an overall measure of the difference between the number of } \\
\text { deaths that have occurred in the period compared with the number expected } \\
\text { based on earlier years - but is a combination of several competing effects that } \\
\text { may cancel each other. }\end{array}$ \\
2. Actual natural deaths v. forecast natural deaths & $\begin{array}{l}\text { This measure aims to remove the effect of the changes to unnatural deaths } \\
\text { during lockdown (since COVID-19 deaths are natural deaths). }\end{array}$ \\
3. Actual natural deaths v. adjusted base for natural deaths & $\begin{array}{l}\text { This measure aims to identify the excess number of natural deaths that might } \\
\text { have resulted from the direct and indirect effects of COVID-19, by taking into } \\
\text { account the fact that lockdown had reduced the number of deaths from other } \\
\text { natural causes. }\end{array}$
\end{tabular}




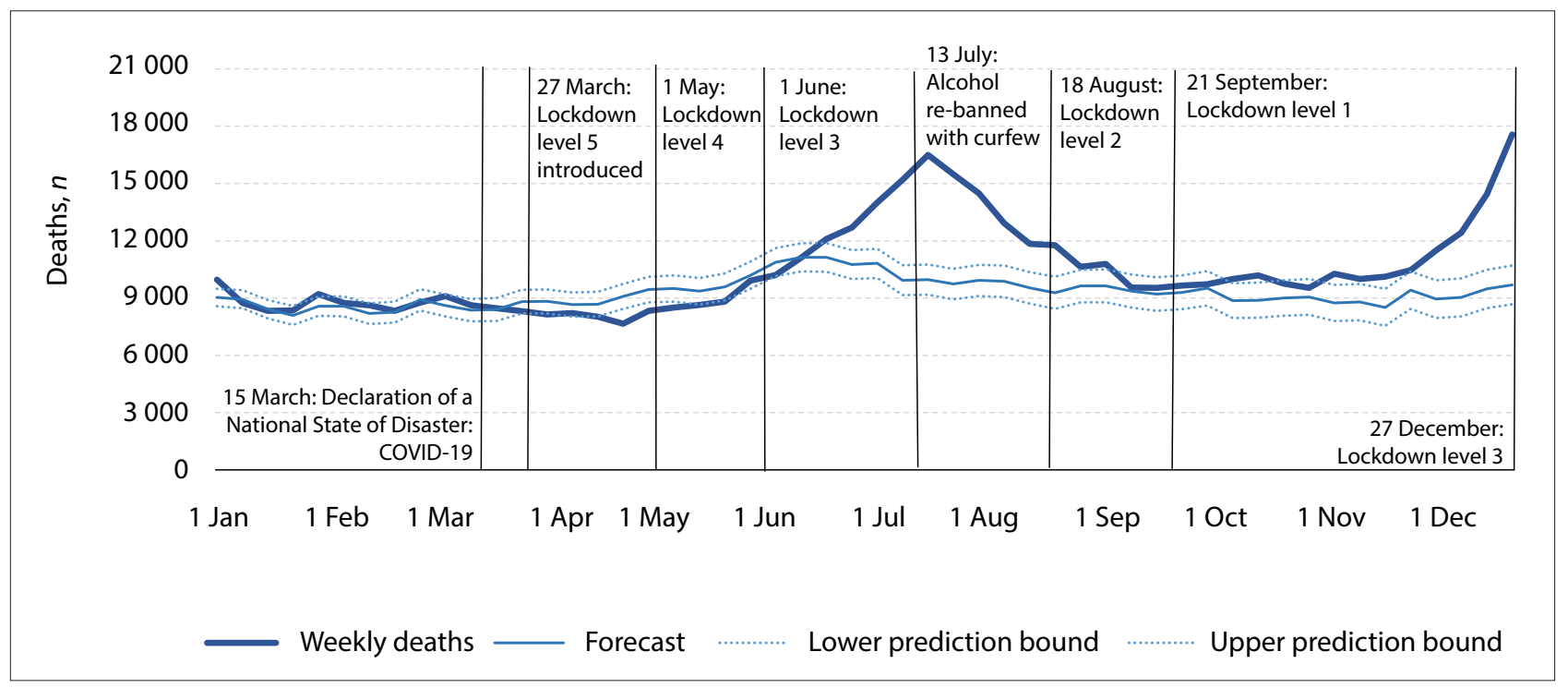

Fig. 1. Number of weekly deaths of persons aged $\geq 1$ year from all causes in South Africa, 2020.

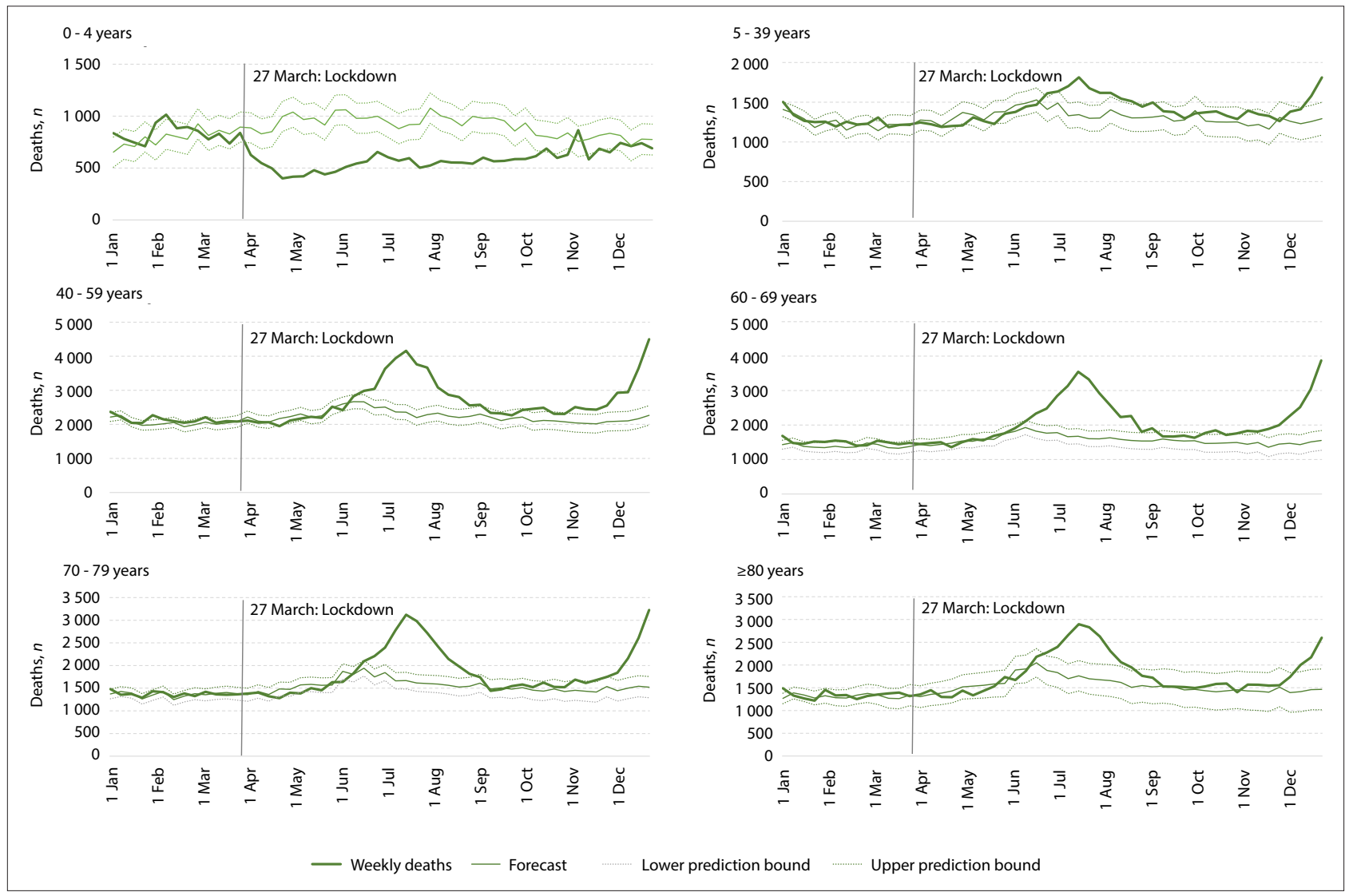

Fig. 2. Number of weekly natural deaths by age group in South Africa, 2020.

$\sim 37 \%$ above the predicted value. The numbers of natural deaths fell below the predicted value for ages $70-79$ and $\geq 80$ years soon after the lockdown before the increase in May, even going significantly higher than the predicted value in June. The 60 - 69-year age group exceeded the upper prediction bounds earliest and experienced the biggest increase during the peak of the first wave for both males and females $(100-120 \%)$. The increase for the younger and older adults was of the order of $70-80 \%$ during the peak, with slight variations by age and sex. While all age groups showed an increase in the number of deaths from natural causes during October, the 40 - 59- and 60 69 -year age groups had exceeded the upper prediction bounds in early November, with other age groups later than this.

The trend in the number of unnatural deaths is shown in Fig. 3 for males and females separately. The numbers showed a very quick response to lockdown, associated with reduced mobility and restrictions on alcohol sales. Numbers of deaths were halved for both males and females. During level 3 lockdown, the number of male deaths initially exceeded the predicted number before falling below 


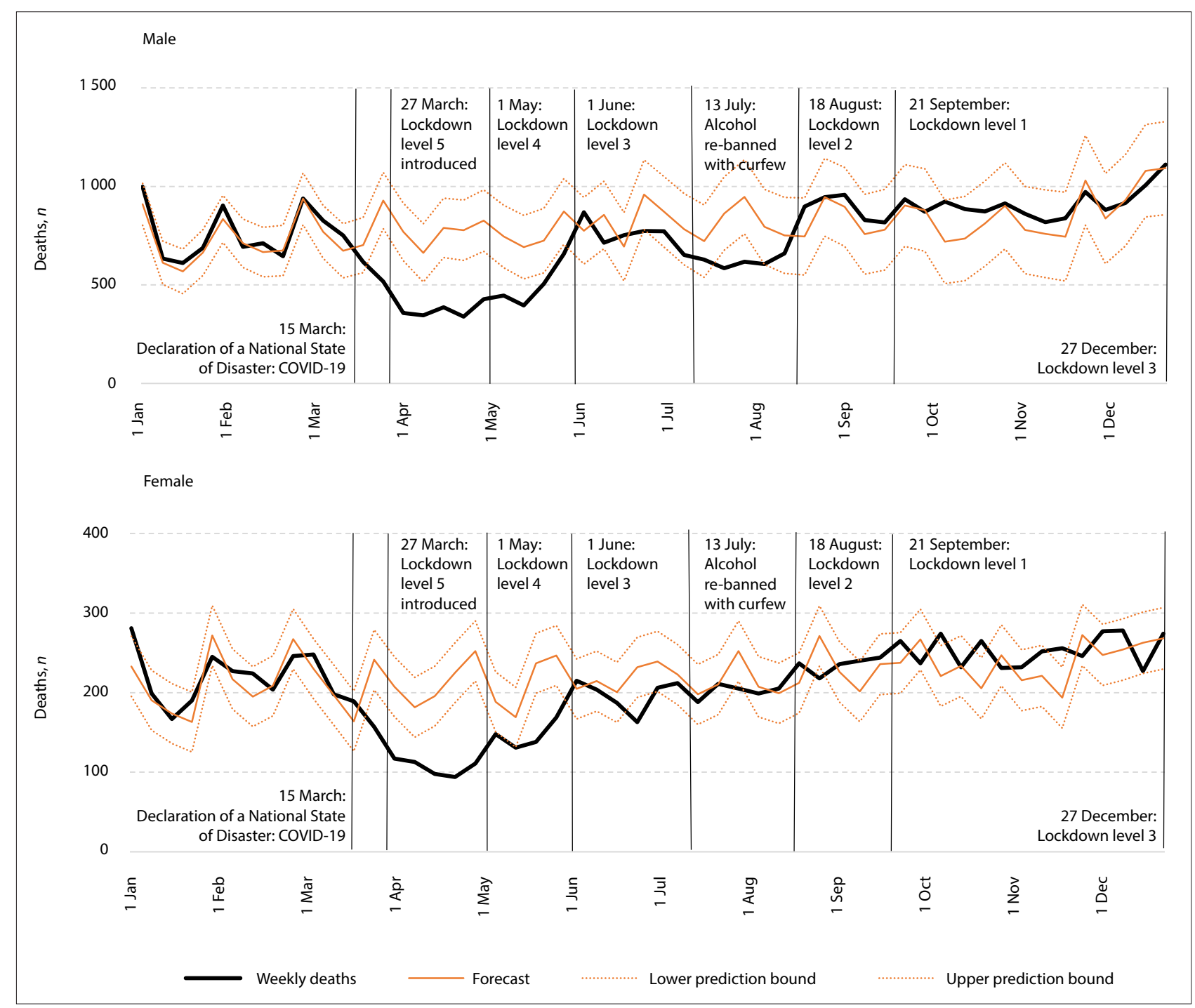

Fig. 3. Number of weekly unnatural deaths $\geq 1$ year by sex in South Africa, 2020.

it, but remaining above the lower prediction bound. It was only after the re-banning of alcohol sales that the weekly number dropped significantly below the predicted level for several weeks. Following the change to level 2 lockdown on 18 August, the number of deaths from unnatural causes remained slightly above the predicted number but generally tracked within the uncertainty bound. Nearly 54000 deaths of persons aged $\geq 1$ year from unnatural causes were predicted for 2020. By the end of the year, just over 49000 deaths had occurred, indicating that $\sim 5000$ unnatural deaths were averted over the year, mostly in the second and third quarters of the year.

Table 2 shows the number of excess deaths calculated using the different approaches and compared with the number of confirmed COVID-19 deaths as reported by the Minister of Health. ${ }^{[17]}$ In total, there were 76127 excess deaths from natural causes when using the base adjusted to reflect that initially non-COVID-19 deaths were below the predicted numbers of deaths as a result of lockdown, more than 2.7 times higher than the confirmed COVID-19 deaths for the year. The gap between the excess natural deaths and the confirmed COVID-19 deaths in Western Cape is the smallest, while the relative discrepancy in Northern Cape and North West provinces are particularly marked. Nationally, there were 70269 excess deaths from all causes. Given the big reduction in unnatural deaths over the year, it may seem surprising that the total number of excess natural deaths was very similar (70 988). The similarity is due to two factors: firstly, more than half the drop in unnatural deaths occurred before the point from which excess deaths were tracked (early May), and secondly, the general practice of setting weekly excess deaths to zero in weeks where the excess deaths are negative has affected the allcause mortality to a greater extent.

The number of excess natural deaths compared with those using the adjusted base in each province is shown in Fig. 4. The timing of the peak of the first wave differed in each province. Excess deaths increased first in Western Cape, maintaining a high level over a more extended period than in the other provinces. Next followed in order Eastern Cape, Gauteng, KwaZulu-Natal and Free State, all with sharper peaks. The waves in the other provinces were smaller. A second wave began in Eastern Cape with a protracted increase in deaths from the beginning of October, followed by Western Cape during November and KwaZulu-Natal during December, suggesting a peak higher than the first.

The age and sex breakdown of the excess natural deaths using the adjusted base is presented in Table 3. In all age groups except the 40 49 -year age group there were more female than male deaths. This is particularly noticeable in the 10 - 19-year age group (which, although 
Table 2. Excess deaths compared with confirmed COVID-19 deaths in South Africa, 2020

\begin{tabular}{lllll}
\hline Region & Excess all-cause deaths & Excess natural deaths & $\begin{array}{l}\text { Excess natural deaths v. } \\
\text { adjusted base }\end{array}$ & $\begin{array}{l}\text { Confirmed COVID-19 } \\
\text { deaths }\end{array}$ \\
\hline $\begin{array}{l}\text { South Africa } \\
\text { Province }\end{array}$ & 70269 & 70998 & 76127 & 28469 \\
$\quad$ Eastern Cape & 23177 & 23301 & 23424 & 7316 \\
Free State & 5267 & 5153 & 5192 & 2168 \\
Gauteng & 14057 & 14514 & 14770 & 5549 \\
KwaZulu-Natal & 12478 & 12965 & 13184 & 4394 \\
Limpopo & 1804 & 1884 & 2684 & 592 \\
Mpumalanga & 3441 & 3588 & 3595 & 644 \\
Northern Cape & 2102 & 2075 & 2024 & 390 \\
North West & 3590 & 3287 & 3226 & 577 \\
Western Cape & 9360 & 8766 & 10540 & 6839 \\
& & & &
\end{tabular}

Table 3. Number of excess natural deaths of persons aged $\geq 1$ year (using adjusted base) and death rates (/100 000 population) by age and sex in South Africa, 2020

\begin{tabular}{|c|c|c|c|c|c|c|c|}
\hline \multirow[b]{2}{*}{ Age group (years) } & \multicolumn{2}{|c|}{ Male } & \multicolumn{2}{|c|}{ Female } & \multirow[b]{2}{*}{$\begin{array}{l}\text { Male/female } \\
\text { ratio of rates }\end{array}$} & \multicolumn{2}{|c|}{ Persons } \\
\hline & $n(\%)$ & $\begin{array}{l}/ 100000 \\
\text { population }\end{array}$ & $n(\%)$ & $\begin{array}{l}/ 100000 \\
\text { population }\end{array}$ & & $n(\%)$ & $\begin{array}{l}/ 100000 \\
\text { population }\end{array}$ \\
\hline $1-9$ & 0 & 0 & 0 & 0 & - & 0 & 0 \\
\hline $10-19$ & $38(0.1)$ & 0.7 & $294(0.7)$ & 5.8 & 0.13 & $332(0.5)$ & 3.2 \\
\hline $20-29$ & $561(1.8)$ & 10.8 & $633(1.6)$ & 12.5 & 0.86 & $1194(1.7)$ & 11.6 \\
\hline $30-39$ & $2017(6.6)$ & 39.4 & $2195(5.4)$ & 44.2 & 0.89 & $4213(5.9)$ & 41.8 \\
\hline $40-49$ & 3265 (10.7) & 95.8 & $3244(8.0)$ & 94.1 & 1.02 & $6509(9.2)$ & 94.9 \\
\hline $50-59$ & 6089 (19.9) & 268.8 & $7792(19.3)$ & 290.5 & 0.93 & 13881 (19.6) & 280.6 \\
\hline $60-69$ & $9209(30.1)$ & 643.0 & $10515(26.1)$ & 577.4 & 1.11 & $19724(27.8)$ & 606.3 \\
\hline $70-79$ & $5958(19.4)$ & 905.7 & $8144(20.2)$ & 866.3 & 1.05 & 14102 (19.9) & 882.5 \\
\hline$\geq 80$ & 3507 (11.4) & 1264.2 & $7503(18.6)$ & 1488.4 & 0.85 & $11010(15.5)$ & 1408.8 \\
\hline Total & $30643(100)$ & 107.0 & $40321(100)$ & 136.6 & 0.78 & $70965(100)$ & 122.0 \\
\hline
\end{tabular}

the numbers are too small to be certain, could reflect an increase in collateral deaths in adolescent girls) and among the elderly (where women outnumber men in the population). One-third of the excess deaths were of persons aged $<60$ years, and two-thirds were of persons who were older. The age group 60 - 69 years had the highest proportion of excess deaths (males and females). Interestingly, in terms of death rates, male mortality rates exceeded those of females in only the 40 - 49 and 60 - 79-year age ranges. Across all ages, the male excess death rate was 0.78 of the female excess death rate.

\section{Discussion}

SA is one of the few low- or middle-income countries able to set up near to real-time monitoring of the number of all-cause deaths. With assumptions about completeness of the NPR data and a small correction for a lag in processing, it has been possible to report on the trend up to a week before the week in which the data are available, both nationally and for each province. The first report on weekly deaths was released at the end of March 2020, ${ }^{[18]}$ the same week that the Minister of Health announced the country's first confirmed COVID-19 death. ${ }^{[19]}$ The government's swift actions to contain the pandemic included, among others, a stringent lockdown, ${ }^{[2]}$ and with almost immediate effect, the weekly number of deaths from unnatural causes dropped to about half the expected number. This drop reduced demands on emergency services and thereby contributed to the strategic intention of buying time to repurpose the healthcare services.
The early tracking of weekly deaths also revealed a surprising decline in the number of natural deaths accompanying the stringent lockdown. This was particularly marked in children but also seen to some extent in adults of all ages except for 60 - 69-year-olds. Influenza surveillance conducted by the Centre for Respiratory Diseases and Meningitis, National Institute for Communicable Disease/National Health Laboratory Service, observed no outbreaks of influenza in the 2020 winter season, in contrast to the experience in countries in the Northern Hemisphere. ${ }^{[21,22]}$ Although the ban on international travel prevented the widespread introduction of seasonal influenza, it is probable that the widespread adoption of community mitigation measures to reduce transmission of SARS-CoV-2 also helped prevent transmission of influenza. It is also possible that these measures helped to reduce the spread of other infectious diseases such as diarrhoea. This drop in the number of natural deaths resulted in the development of the adjustment to the base to calculate the excess natural deaths.

The 60 -69-year-olds were most affected at the peak of the surge, accounting for $28 \%$ of the excess natural deaths, the highest proportion of all 10-year age groups, and similar to the proportion of confirmed COVID-19 deaths in the first months of the pandemic $(26 \%),{ }^{[23]}$ as well as deaths reported on the hospital surveillance system by the end of 2020 (27\%). ${ }^{[24]}$ It is possible that excess deaths due to COVID-19 occurred earlier in this age group than in other age groups, obscuring any drop in the number of deaths resulting from lockdown. A higher proportion of the excess natural deaths were of 


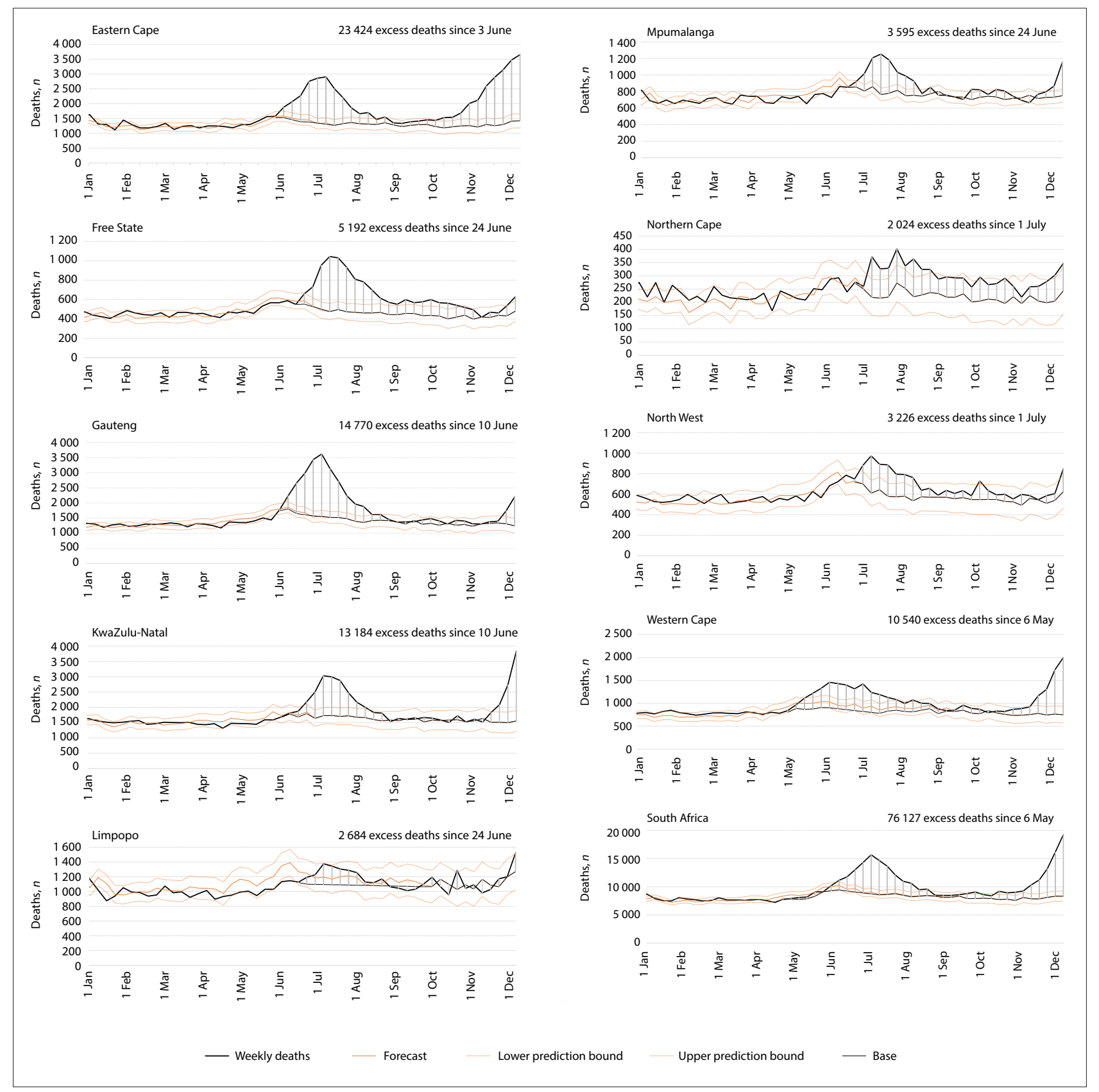

Fig. 4. Number of excess natural deaths $\geq 1$ year relative to adjusted base by province in South Africa, 2020.

persons aged $\geq 80$ years $(16 \%)$ than of the reported confirmed COVID19 deaths (11\%) or of COVID-19 deaths (13\%) reported through the hospital surveillance system. It is possible that deaths among elderly people, particularly women, disproportionately occurred in care institutions or communities without accessing health services.

Depending on definition, 70000 - 76000 excess deaths occurred in 2020 over the months of the COVID-19 epidemic. In comparison, there were 73500 deaths due to HIV/AIDS in $2020,{ }^{[25]}$ which would have been the leading single cause of death in the absence of the epidemic. In common with HIV/AIDS, but in contrast with many (if not most) other countries, there is a greater number of deaths (and higher per capita mortality rate) in women than in men. However, the impact on life expectancy at birth was, perhaps surprisingly, minimal (a decline of a year for females and a slight improvement for males) as a result of both the age distribution of COVID-19 deaths and the decline in non-COVID-19 deaths in most ages, particularly infants and children.

Owing to the effects of the early lockdown in SA, the excess deaths from natural causes less the adjusted baseline are likely to be the best indication of the impact of COVID-19-related deaths (i.e. the underlying cause of death was COVID-19, or COVID-19 was a contributory condition). The temporal trend and the age pattern of the excess deaths suggest that most of these deaths are directly due to or related to COVID-19. ${ }^{[26]}$ Given the high correlation between the numbers per week over time with the confirmed deaths by week of death, we consider that at least $85 \%$ of the excess natural deaths were due to COVID-19. This is much higher than the 28469 officially confirmed COVID-19 deaths. Allowing for this and the relatively young population, COVID-19 deaths per capita in SA probably ranked in the top five countries in the world. 
The under-identification of COVID-19 deaths is not unique to SA. Based on data on available excess death data, Karlinsky and Kobak ${ }^{[27]}$ estimate that the death toll from COVID-19 has been much higher than the reported COVID-19 deaths in many countries, particularly countries in Eastern Europe and South America. Considering the situation in the USA, Kiang et al. ${ }^{[28]}$ argue that the true number of deaths resulting from COVID-19, both directly and indirectly, is likely to be much higher than the registered deaths with this cause. They highlight the value of monitoring excess deaths and stress the importance of reporting a measure of the uncertainty about the estimate. Further investigations are needed to model the excess mortality in SA, including bounds of uncertainty.

Kiang et al. ${ }^{[28]}$ also highlight the importance of information about the causal sequence of conditions resulting in death in order to assess the direct and indirect impact of COVID-19. The collection of causeof-death information in SA is paper based, resulting in substantial delays in the processing of such information. Furthermore, following the amendment to the Births and Deaths Registration Act No. 51 of 1992 in 2014, the National Department of Health (NDoH) is no longer able to access identified information recorded by doctors on the death notification form (DHA-1663), ${ }^{[29]}$ making it impossible for the Department to utilise information from death notification forms for contact tracing or epidemiological purposes. There is an urgent need for the departments of Home Affairs and Health and Stats SA to re-engineer the country's civil registration and vital statistics process to support public health actions and allow the country to monitor COVID-19 and its long-term consequences, and to tease out the impact of COVID-19 from collateral deaths arising from the socioeconomic impacts of lockdown.

\section{Study limitations}

The method of estimating excess deaths on a weekly basis was devised at short notice and has a number of weaknesses. The method of projecting the expected numbers of non-COVID-19 deaths in 2020 was based on data covering only 2018 and 2019 and produced an expanding projection interval over time. Stats SA has released a further year (2017) of cause-of-death data that were not considered in the estimates of completeness. These limitations have been addressed in the ongoing monitoring of the epidemic in 2021. However, it remains unknown exactly what proportion of excess deaths were due to COVID-19 (directly or indirectly) and the true range of uncertainty about the estimate of excess deaths.

\section{Conclusions}

SA has been able to monitor excess deaths in near real time by making use of data from the NPR. This tracked the first wave during the middle of 2020 and the emergence of a substantial second wave during the last months of the year, resulting in 76000 excess deaths from natural causes during 2020. The confirmed COVID-19 deaths understate the death toll from the pandemic by a factor of 2.7. Furthermore, the data have also revealed unintended consequences of lockdown, including a significant drop in the number of deaths from unnatural causes and a reduction in deaths from influenza and other infections.

Government is urged to improve the cause-of-death information system going forward so that the current and long-term impact of the pandemic can be assessed more fully and information to prioritise responses can become available. ${ }^{[23]}$ In particular, it is essential to ensure that the $\mathrm{NDoH}$ has access to cause-of-death information at the time of death registration to inform public health actions. ${ }^{[29]}$

\section{Declaration. None.}

Acknowledgements. The DoHA is thanked for providing weekly data from the NPR.

Author contributions. All authors contributed to the concept, the interpretation of the data and the presentation of the results. RL maintains the database for the death data, including quality controls. RED estimated the correction factors to account for under-registration of deaths and the adjustment for the base for calculation of excess deaths. All authors contributed to the writing of the paper, which was initially drafted by DB and RED.

Funding. The SAMRC has supported DB, RL and PG. RED and TAM have been funded by the University of Cape Town.

Conflicts of interest. None.

1. Giattino C. How epidemiological models of COVID-19 help us estimate the true number of infections. Our World in Data, 24 August 2020 https://ourworldindata or $/$ /covid-models (accessed 30 October 2020).

2. Aron I, Muellbauer J, Giattino C, Ritchie H. A pandemic primer on excess mortality statistics and their comparability across countries. Our World in Data, 29 June 2020. https://ourworldindata.org/covidcomparability across countries. Our World in D.

3. Woolf SH, Chapman DA, Sabo RT, Weinberger DM, Hill L. Excess deaths from COVID-19 and other Woolf SH, Chapman DA, Sabo RT, Weinberger DM, Hill L. Excess deaths from COVID-19 and o
causes, March - April 2020. JAMA 2020;324(5):510-513. https://doi.org/10.1001/jama.2020.11787

4. Weinberger DM, Chen J, Cohen T, et al. Estimation of excess deaths associated with the COVID-19 pandemic in the United States, March to May 2020. JAMA Int Med 2020;180(10):1336-1344. https:// doi.org/10.1001/jamainternmed.2020.3391

5. Beaney T, Clarke JM, Jain V, et al. Excess mortality: The gold standard in measuring the impact of COVID-19 worldwide? J R Soc Med 2020;113(9):329-334. https://doi.org/10.1177/0141076820956802 6. Leon DA, Shkolnikov VM, Smeeth L, Magnus P, Pechholdová M, Jarvis CI. COVID-19: A need for real-time monitoring of weekly excess deaths. Lancet 2020;395(10234):e81. https://doi.org/10.1016/ s0140-6736(20)30933-8

7. Joubert J, Rao C, Bradshaw D, Vos T, Lopez AD. Evaluating the quality of national mortality statistics from civil registration in South Africa, 1997-2007. PLoS ONE 2013;8(5):e64592. https://doi. statistics from civil registration in

8. Statistics South Africa. Mortality and causes of death in South Africa, 2017: Findings from death 8. Statistics South Africa. Mortality and causes of death in South Africa, 2017: Findings from death
notification. Statistical release P0309.3. Pretoria: Stats SA, 2020. https://www.statssa.gov.za/ publications/P03093/P030932017.pdf (accessed 30 October 2020)

9. Dorrington RE, Bradshaw D, Laubscher R, Nannan N. Rapid mortality surveillance report 2018. Cape Town: South African Medical Research Council, 2020. https://www.samrc.ac.za/sites/default/files/ files/2020-03-02/RapidMortalitySurveillanceReport2018.pdf (accessed 20 April 2021)

10. Minister of Home Affairs. Office hours during South Africass lockdown. 31 March 2020. http:// www.dha.gov.za/index.php/statements-speeches/1334-office-hours-during-south-africa-s-lockdown (accessed 30 October 2020).

11. Dorrington RE. The generalized growth balance method. In: Moultrie TA, Dorrington RE, Hill AG, Hill KH, Timæus IM, Zaba B, eds. Tools for Demographic Estimation. Paris: International Union for the Scientific Study of Population, 2013.

12. Dorrington RE. The Synthetic Extinct Generations method. In: Moultrie TA, Dorrington RE, Hill AG, Dorrington RE. The Synthetic Extinct Generations method. In: Moultrie TA, Dorrington RE, Hill AG,
Hill KH, Timæus IM, Zaba B, eds. Tools for Demographic Estimation. Paris: International Union for the Scientific Study of Population, 2013

13. National Department of Health, Statistics South Africa, South African Medical Research Council and ICF. South Africa Demographic and Health Survey 2016. Pretoria, South Africa and Rockville, Md, USA: NDoH, Stats SA, SAMRC and ICF, 2019. www.statssa.gov.za/publications/Report\%2003-00-09/ Report\%2003-00-092016.pdf (accessed 20 October 2020).

14. Holt CC. Forecasting seasonals and trends by exponentially weighted averages Int J Forecast 1957;20(1):5-10. https://doi.org/10.1016/j.ijforecast.2003.09.015

5. Winters PR. Forecasting sales by exponentially weighted moving averages. Manage Sci 1960;6(3):231362. https://doi.org/10.1287/mnsc.6.3.324

16. World Health Organization. Humanitarian Health Action. Definitions: Emergencies. 2008. https:// www.who.int/hac/about/definitions/en/ (accessed 30 October 2008).

17. National Department of Health, South Africa, COVID-19 Online Resource \& News Portal. Update on Covid-19 (31st December 2020). Media statement, 31 December 2020. https://sacoronavirus. on Covid-19 (31st December 2020). Media statement, 31 December 2020. https:

18. Bradshaw D, Laubscher R, Dorrington R, Groenewald P, Moultrie TA. Report on weekly deaths in South Africa: 1 January - 15 March 2020. Burden of Disease Research Unit, South African Medical South Africa: 1 January - 15 March 2020. Burden of Disease Research Unit, South African Medical
Research Council, 20 March 2020. https://www.samrc.ac.za/sites/default/files/files/2020-04-17/ WeeklyDeaths_15March2020.pdf (accessed 11 October 2020).

19. National Department of Health, South Africa. Minister Zweli Mkhize confirms first deaths due to Coronavirus COVID-19. 27 March 2020. https://www.gov.za/speeches/minister-zweli-mkhizeconfirms-first-deaths-due-coronavirus-covid-19-27-mar-2020-0000 (accessed 11 October 2020).

20. Abdool Karim SS. The South African response to the pandemic. N Engl J Med 2020;382(24):e95, https://doi.org/10.1056/NEJMc2014960

21. National Institute for Communicable Diseases. Influenza. Communicable Diseases Communique June 2020;19(6):5. https://www.nicd ac za/wp-content/uploads/2020/07/NICD-Communicable-DiseaseCommunique-June-2020-Issue pdf (accessed 11 October 2020).

22. Olsen SJ, Azziz-Baumgartner E, Budd AP, et al. Decreased influenza activity during the COVID-19 pandemic - United States, Australia, Chile, and South Africa, 2020. MMWR Morb Mortal Wkly Rep pandemic - United States, Australia, Chile, and South Africa, 2020. MM

23. Pillay-van Wyk V, Bradshaw D, Groenewald P, et al. COVID deaths in South Africa: 99 days since Pillay-van Wyk V, Bradshaw D, Groenewald P, et al. COVID deaths in South Africa: 99 days since
South Africass first death. S Afr Med J 2020;110(11):1093-1099. https://doi.org/10.7196/SAMJ.2020. v110i11.15249

24. National Institute for Communicable Diseases DATCOV19 Platform. NICD COVID-19 surveillance in selected hospitals. 7 October 2020. https://www.nicd.ac.za/wp-content/uploads/2020/10/NICDCOVID-19-Daily-Sentinel-Hospital-Surveillance-report-PRIVATE-20201007.pdf (accessed 11 October 2020). 
25. Johnson LF, May MT, Dorrington RE, et al. Estimating the impact of antiretroviral treatment on adult mortality trends in South Africa: A mathematical modelling study. PLoS Med 2017;14(12):e1002468. https://doi.org/10.1371/journal.pmed.1002468

26. Moultrie TA, Dorrington R, Laubscher R, Groenewald P, Bradshaw D. Correlation of excess natural

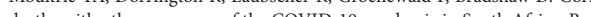
deaths with otricase Rurden of Disease Research Unit, South African Medical Research Council, 2021. https://www.samrc.ac.za/sites/default/files/ files/2021-03-03/CorrelationExcessDeaths.pdf (accessed 18 April 2021).

27. Karlinsky A, Kobak D. The World Mortality Dataset: Tracking excess mortality across countries during the COVID-19 pandemic. medRxiv 2021 (epub 11 April 2021). https://doi. org/10.1101/2021.01.27.21250604
28. Kiang MV, Irizarry RA, Buckee CO, Balsari S. Every body counts: Measuring mortality from the COVID-19 pandemic. Ann Intern Med 2020 (epub 15 December 2020). https://doi.org/10.7326/m20-3100

29. Groenewald P, Azevedo V, Daniels J, et al. The importance of identified cause-of-death information being available for public health surveillance, actions and research. S Afr Med J 2015;105(7):528-530. https://doi.org/10.7196/SAMJnew.8019

Accepted 13 May 2021 